\title{
Effect of Mixing Individual Isolates for Bioreduction of Metals in Contaminated Soil
}

\author{
Emenike C. U. ${ }^{1,2^{*}}$, Izyani A. K. ${ }^{2}$, Fauziah S. H. ${ }^{2}$ \\ ${ }^{1}$ Centre for Research in Waste Management, Faculty of Science, University of Malaya, Kuala Lumpur, \\ Malaysia. \\ 2 Institute of Biological Sciences, Faculty of Science, University of Malaya, Kuala Lumpur, Malaysia. \\ * Corresponding author. Tel.: +603-79674631; email: emenike@um.edu.my, emenikecu@gmail.com \\ Manuscript submitted November 7, 2016; accepted March 23, 2017. \\ doi: 10.17706/ijbbb.2017.7.3.194-200
}

\begin{abstract}
Bioremediation of metal contaminated soil involves complex processes, and the non-degradable nature of metals makes it more difficult. The known sources of metal pollution are many and adopting a specific remediation procedure for it is often impossible. Microbes found at polluted sites tend to serve as good remediation agents due to perceived environmental potential. Therefore, it is imperative to select bioremediation by enhancing microbes potential as a way of restoring metal polluted site to original or undisturbed state. Hence, this study tried to evaluate the individual effect of bacterial isolates on the remediation of metal polluted soil from landfill, against combined impact of microbes blended together. Soil samples that characterized of $\mathrm{Cd}^{2+}, \mathrm{Cr}^{2+}, \mathrm{Pb}^{2+}$ and $\mathrm{Zn}^{2+}$ were subjected to bioremediation. Results revealed no more than $50 \%$ reduction across the treatments amended with individual isolates. Rather higher metal remediation was observed when individual isolates were mixed prior to application. Therefore, the study suggests that individual isolates from contaminated sites can selectively metabolize to bioreduce metal concentrations. However, a mix of such isolates with manipulation in the concentration level can enhance metal reduction efficiency $(>50 \%)$.
\end{abstract}

Key words: Bioaugmentation, bioremediation, metal pollution, leachate.

\section{Introduction}

Environmental restoration/recovery is the core way of maintaining a functional ecosystem affected by pollution/contamination. One common method of environmental restoration is bioremediation of contaminated environments, especially soil core. Inundation of most soil cores with metals above natural occurrence levels is common, and this pose ecological risk to both humans and lower organisms, including microbes. Metal pollution of soil is common due to the recent wave of industrialization and economic development. This developmental problem is common with the developing economies of the world and other nations that are not up-to-date with the state-of-the-art technologies that minimize pollution. Prevalent in such communities is metal pollution that often emanate from indiscriminate metal waste disposal, landfilling and mine tailings. Leachate from landfills is a major pollutant fluid that contains metals, and easily permeate soil core, groundwater and even runs off into surface water. In fact, metals from leachate mobilize even kilometres away from landfill site [1]. Hence, this is the reason bioremediation of leachate-metal polluted soil is very important. A sustainable soil remediation approach is any method that involves technical removal of pollutants while soil quality and functioning are preserved [2], [3]. Basically, 
bioremediation is primarily the use of degrader microbes, but the toxic level of contaminants within a polluted soil environment may only allow the survival of some microbes rather than giving chance for pollutant degradation (in case of most organic compounds) or transformation (in case of most inorganic compounds like metals) [4]. However, when microbes are properly engineered or enhanced with respect to population, biochemical properties and diversity, they tend to optimally metabolize pollutants; metals inclusive [2]. Some bacteria species possess remediation potentials for metal pollution [5], [6]. It implies that bioaugmentation of metal polluted soil with desired microbial strain is of significant interest towards restoration of metal impacted soil. Individual strains may have varying capabilities towards polluted systems, and synergizing the potentials such of microbial strains may yield optimal response to metal pollution. Therefore, this study was designed to establish the metal remediation potentials of individual bacterial strains isolated from leachate inundated environment, and similarly evaluate the efficiency of metal reduction when bacterial strains are blended together prior to application.

\section{Materials and Methods}

Leachate contaminated soil and raw leachate samples were taken from a sanitary landfill $\left(3027.63^{\prime} \mathrm{N}\right.$, 10100.2.54'E) for microbial isolation and characterization, respectively, whereas uncontaminated fresh soil samples were collected from garden $\left(307^{\prime} 24.15 \mathrm{~N}, 101039^{\prime} 16.79^{\prime \prime} \mathrm{E}\right)$ for induced contamination experiment. Soil contamination by leachate was done at laboratory condition and its treatment was monitored there. Hence, $2 \mathrm{~kg}$ of the soil samples were weighed into perforated plastic bags, and subsequently contaminated with leachate $(10 \% \mathrm{v} / \mathrm{w})$. The contaminated soil samples were allowed to stand for 48 hours for pre-diffusion of leachate into the soil system.

Subsequently, bacterial species isolated from the contaminated landfill soil were reactivated and sub-cultured using Nutrient Broth E and Nutrient Agar, respectively, in accordance to standard methods. Individual microbes, namely Bacillus sp, Lysinibacillus sp and Rhodococcus sp were used to prepare discrete inoculums in flasks containing Nutrient Broth $\mathrm{E}$ after steady growth phase was reached (1.3 ABS at OD600nm). Microcosms (4) were set-up based on amendment with individual inoculums; hence the treatments were designated A (amended with Bacillus sp), B (amended with Lysinibacillus sp), C (amended with Rhodococcus $\mathrm{sp}$ ) and D (control without any amendment). Each treatment was set-up in triplicates. Another microcosm that contained mixture of inoculums of all isolated bacteria strains was prepared after monitoring the performance of the individual isolates.

About $60-65 \%$ soil moisture level was maintained throughout the experiment, and the bioremediation activity was monitored at 20 days intervals for the next 100 days. Some physicochemical properties of the soil were observed alongside the microbial population within the system. Samples taken on each day of monitoring were duly analyzed for metal concentration. To $0.5 \mathrm{~g}$ of each soil sample, HNO3 and H2O2 were added [7] for acid digestion using Multiwave 3000 microwave digester (Perkin-Elmer/Anton Paar). Subsequently, the elemental concentrations were measured with Optima 5300 DV (Perkin-Elmer, Massachusetts, USA). Evaluation of a procedure blank was always carried out and other experimental precautions were taken. The study used Equation 1 to evaluate the efficiency of the system on metal reduction.

$$
\% \text { of heavy metal removal }=\left(\frac{\operatorname{Co}(x)-C F(x)}{\operatorname{Co}(x)}\right) \times 100 \%
$$

where

Co $(\mathrm{x})=$ Initial reading of heavy metal concentration at 0th day

$\mathrm{CF}(\mathrm{x})=$ Reading of heavy metal concentration at 100th day 


\section{Results and Discussion}

Two of the bacteria strains isolated from the contaminated soil namely, Bacillus sp and Lysinibacillus sp belong the genera class of Bacilli, while the other, Rhodococcus sp is a genera of Actinobacteria. All the bacterial species belong to the $\gamma$-proteobacteria group and represent a core component of native bacteria community often found in soil and on phylogenetic tree [3]. Hence, there is no anticipation that utilizing such microbes in bioremediation will cause significant alteration to the normal microbial structure in the soil. Table. 1 shows the concentrations of the studied metals at the start and end of the bioremediation study.

Table 1. Metal Distribution across the Treated Soil Microcosms

\begin{tabular}{lllll}
\hline Metals & Cd & Cr & Pb & Zn \\
& & & & \\
\hline Initial Conc. (mg/kg) & 1.3 & 10 & 70.4 & 121 \\
Treatment A & & & & \\
a (mg/kg) & & & & \\
b (\%) & 1.2 & 9 & 60.8 & 91 \\
& 7.6 & 10 & 13.6 & 25 \\
& & & & \\
Treatment B & & & & \\
a (mg/kg) & 1.1 & 8 & 61.8 & 79 \\
b (\%) & 15.3 & 20 & 12.2 & 34.7 \\
& & & & \\
& & & & \\
Treatment C & & & & \\
a (mg/kg) \\
b (\%)
\end{tabular}

About 35\% of $\mathrm{Zn}$ was reduced from Treatment B. It reflected the highest percentage for $\mathrm{Zn}$, and other metals reduced across all the treatments characterized of individual isolates. Despite non-addition of inoculum to Treatment $\mathrm{D}$, it still indicated that $16.5 \%$ of $\mathrm{Zn}$ reduction. This might be due to the presence of pre-existing microbes in the leachate-induced soil, and such microbes may have the capacity to reduce or transform portion of heavy metals [8] without prior amendment. Similarly, Treatment A recorded up to $25 \%$ reduction, which may be influenced by pH distribution (Fig. 1). Krishna et al [9] also recorded 25\% of Zn reduction at neutral $\mathrm{pH}(\mathrm{pH} 7)$. However, the reductions appear to be in close range across the treatments, yet the variations could be significantly traced to the individual isolates used as inoculants.

Furthermore, the maximum $\mathrm{Pb}$ reduction was $25 \%$ recorded at Treatment $\mathrm{C}$, while $15.3 \%$ was the highest reduced Cd concentration in Treatments B and C. Basically, the result showed that each treatment amended with any of the isolates yielded more metal reduction than the control experiment (no additional microbial augmentation). The degree of metal reduction across all amended treatments were less than $50 \%$ and does not reflect the optimal impact of microbes as good remediates. However, the distribution of the reduction 
showed that immobilization was taking place, and can be a good indication of the potentials of the utilized bacteria species. In fact, the measured redox potential across treatments (Fig. 2) may indicate promising impact of the microbes because variation of redox potential indicates solubility of metals in contaminated soil.

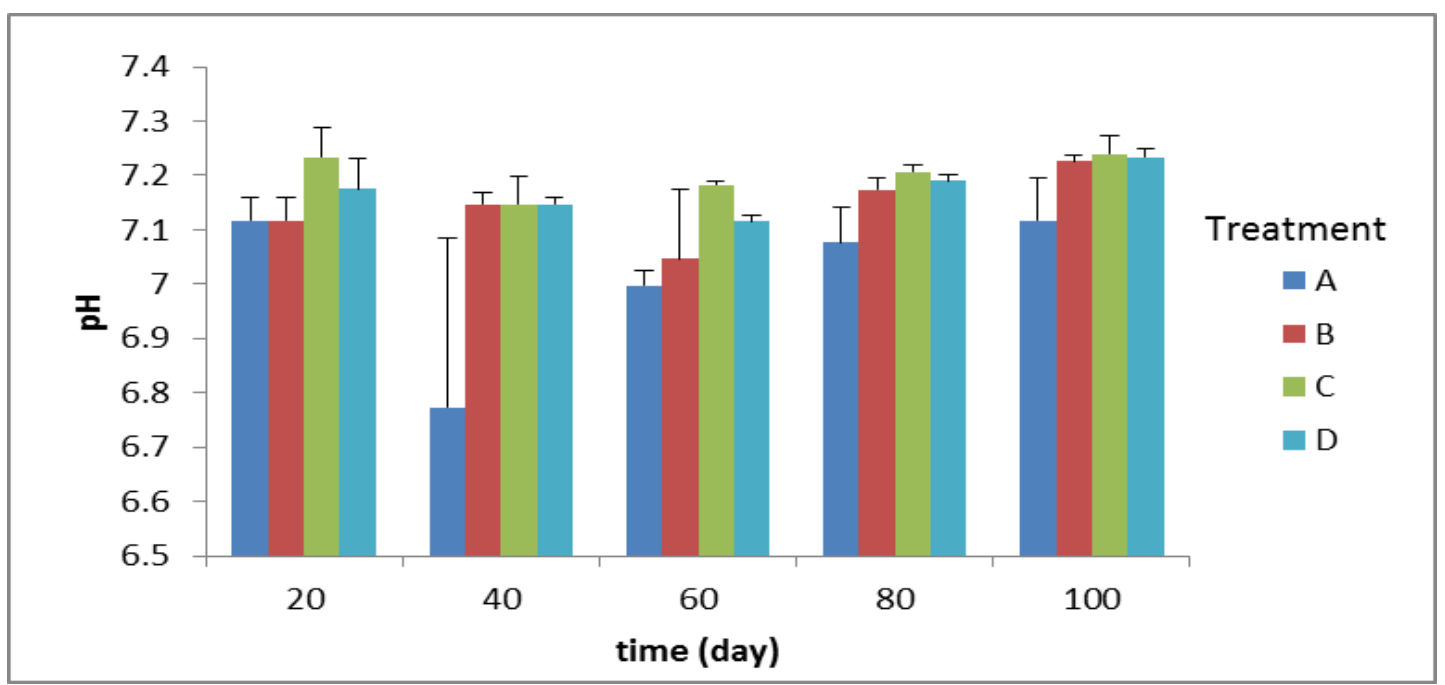

Fig. 1. pH values for each individual isolate treatment during bioremediation.

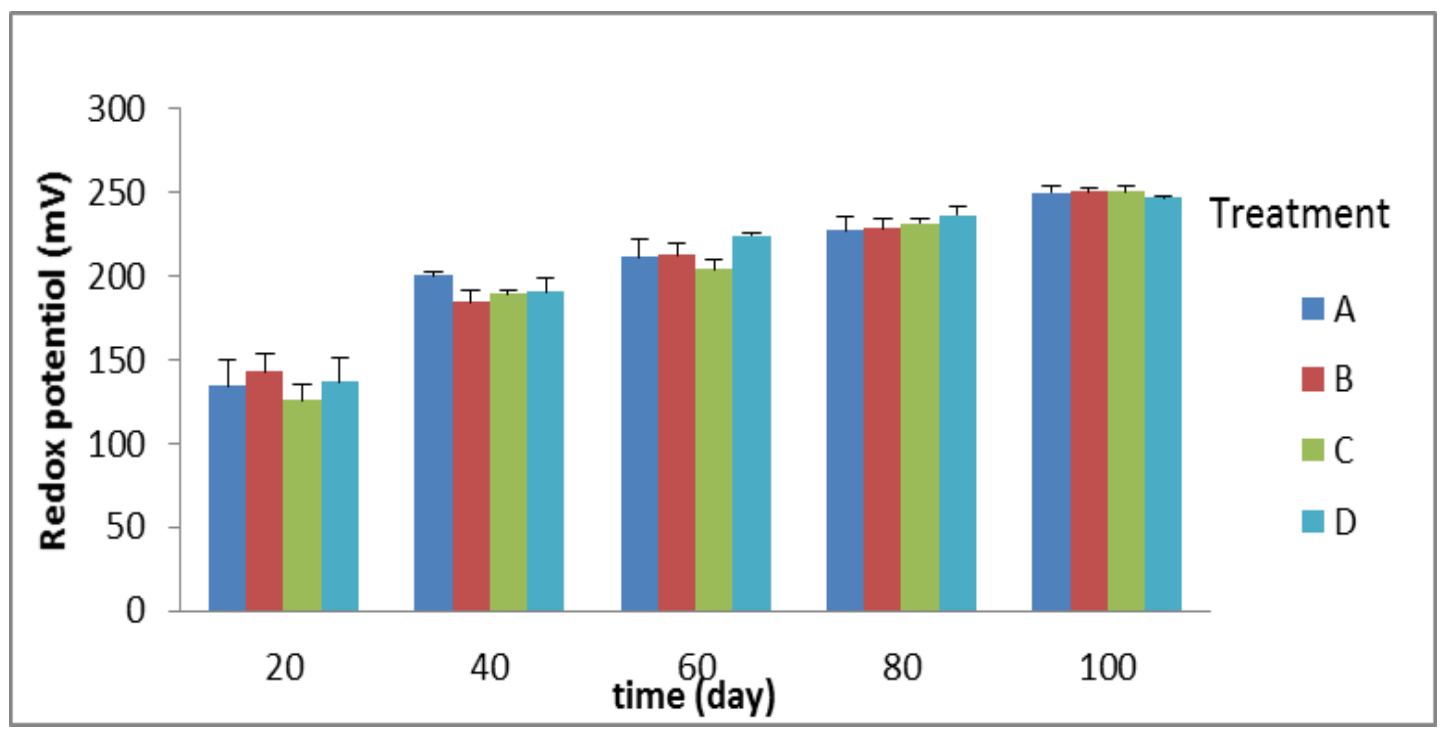

Fig. 2. Redox potential (Eh) values for each individual isolate treatment during bioremediation.

At 20th day of bioremediation, Treatment $\mathrm{C}$ showed the lowest value in Eh (125.56 mV), meanwhile Treatment B showed the highest with $142.9 \mathrm{mV}$. However, at final day of bioremediation, all treatments showed increase in redox potential value with no significant difference across the treatments; hence the ANOVA test, showed that $\mathrm{p}>0.05$ and the $\mathrm{F}$ value is $(\mathrm{df}=4,70) 0.058$. In general, this is an indication that metal reduction was taking place because increase in Eh is a reflection of decrease in solubility of metals in contaminated soil [10], [11]. With the increased Eh, we can assume that the concentration of metals in leachate contaminated soil decreases while undergoing bioremediation.

The individual assessment of the treatments showed that Treatment B recorded the highest reduction potential for the metals. It may be easy to assume that Treatment A will be more promising than others will, considering that Bacillus sp has been reported to be a good remediation agent, especially B.thuringiensis, 
B.cereus and B.anthracis [5], [12], [13]. However, Lysinibacillus sp often show pronounced bioremediation impact by providing a metal binding site [14], and could be the reason why Treatment B recorded the highest reduction level than others. Therefore, mixing the three bacterial isolates at equal proportions and used on leachate-metal induced soil to evaluate the potential impact on metal reduction in contaminated soil, Fig. 3 showed that more than $50 \%$ of the metals recorded significant reduction except for Cd (41.2\%). At this point $\mathrm{Cr}$ reduction was the highest (81\%) after 100 days of monitoring. It is possible that the metal binding effect of Lysinibacillus sp was enhanced and better expressed when in association with Bacillus sp and Rhodococcus sp which are also gram-positive bacteria [2]. Mechanisms behind the enhanced result may also be associated with increase in microbial population within a polluted environment, but most significant is the manipulation of microbial diversity. Blending microbes that exhibit mutual interaction may give optimal metabolic impact on pollutant degradation or transformation.

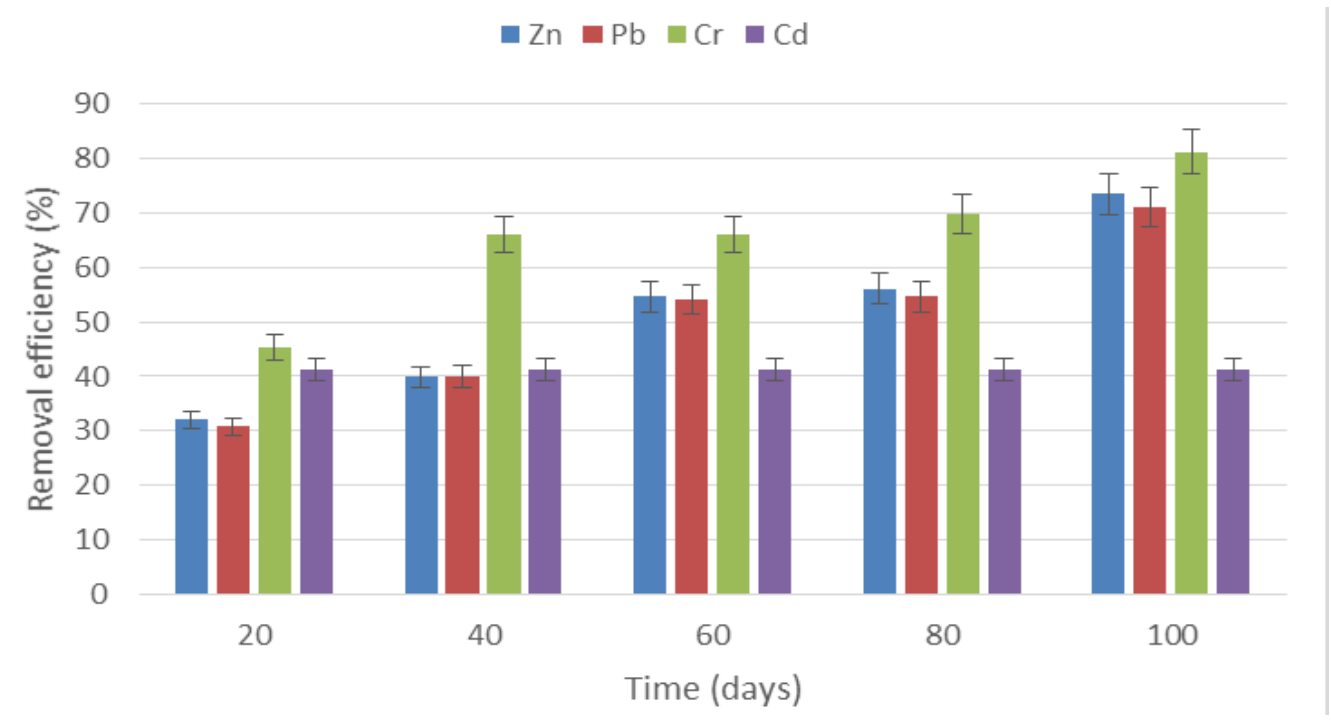

Fig. 3. Metal removal efficiency of the mixed inoculum during bioremediation.

\section{Conclusion}

The present study deduced that leachate can induce metal pollution of soil, and the use of microbes isolated from such environment have the potential to metabolize and enhance more than $70 \%$ metal reduction. However, the microbes will not be significantly effective except the microbial population is increased. Furthermore, it was evident that the manipulation of microbial diversity allows bacteria species to perform optimally than when used as individual isolates. The individual isolates could only reduce about $8-35 \%$ of $\mathrm{Cd}, \mathrm{Cr}, \mathrm{Pb}$ and $\mathrm{Zn}$, and does not reflect significant remediation activity. However, Bacillus $s p$ when blended with Lysinibacillus sp and Rhodococcus sp can effectively reduce metal concentration in leachate-polluted soil. The reduction/immobilization efficacy of the inoculum is $70-80 \%$ for the identified metals except for $\mathrm{Cd}(41 \%)$.

\section{Acknowledgment}

Authors would like to appreciate the sponsorship from University of Malaya Research Grant (RP011A-14SUS) and Centre of Research Grant Management (PG070-2014B).

\section{References}

[1] Emenike, C. U., Agamuthu, P., \& Fauziah, S. H. (2012). Characterization and toxicological evaluation of 
leachate from closed sanitary landfill. Waste Management \& Research, 30(9), 888-897.

[2] Emenike, C. U., Agamuthu, P., \& Fauziah, S. H. (2016). Blending bacillus sp., Lysinibacillus sp. and Rhodococcus sp. for optimal reduction of heavy metals in leachate contaminated soil. Environmental Earth Sciences, 75(26).

[3] Sprocati, A. R., Alisi, C., Tasso, F., Marconi, P., Sciullo, A., \& Pinto, V., et al. (2011). Effectiveness of a microbial formula as a bioaugmentation agent, tailored for bioremediation of diesel oil and heavy metal co-contaminated soil. Process Biochemistry, 47, 1649-1655.

[4] Whiteley, C. G., \& Lee, D. J. (2006). Enzyme technology and biological remediation. Enzyme and Microbial Technology, 38, 291-316.

[5] Babu, A. G., Kim, J., \& Oh, B. (2013). Enhancement of heavy metal phytoremediation by Alnus firma with endophytic Bacillus thuringiensis GDb-1. Journal of Hazardous Materials, 250-251, 447-483.

[6] Rani, A., Souche, Y. S., \& Goel, R. (2009). Comparative assessment of in situ bioremediation potential of cadmium resistant acidophilic Pseudomonas putida 62BN and alkalophilic Pseudomonas montelli 97AN strains on soyabean. International Biodeterioration \& Biodegradation, 63, 62-66.

[7] Hseu, Z. Y., Chan, Z. S., Tsai, C. C., Tsui, S. F., Cheng, S. F., Liu, C. L., \& Lin, H. T. (2002). Digestion methods for total heavy metals in sediments and soils. Water, Air, \& Soil Pollution, 141, 189-205.

[8] Mrozik, A., \& Piotrowska, S. (2010). Bioaugmentation as a strategy for cleaning up of soils contaminated with aromatic compounds. Microbiological Research, 165(5), 363-375.

[9] Krishna, M. P., Varghese, R., Babu, A. V., Jyothy, S., \& Hatha, A. A. M. (2013). Bioremediation of zinc using Bacillus sp isolated from metal-contaminated industrial zone. Prospects in Bioscience: Addressing the Issues, 11-18. Springer India.

[10] Chuan, M. C., Shu, G. Y., \& Liu, J. C. (1995). Solubility of heavy metals in a contaminated soil: Effects of redox potential and pH. Water, Air, \& Soil Pollution, 90(3-4), 543-556.

[11] Yamaguchi, N., Nakamura, T., Dong, D., Takahashi, Y., Amachi, S., \& Makino, T. (2011). Arsenic release from flooded paddy soils is influenced by speciation, Eh, $\mathrm{pH}$ and iron dissolution. Chemosphere, 83, 925-932.

[12] Pepe, O., Sannino, L., Palomba, S., Anastasio, M., Blaiotta, G., Villani, F., \& Moschetti, G. (2010). Heterotrophic microorganisms in deteriorated medieval wall paintings in Sothern Italian churches. Microbiological Research, 165, 21-32.

[13] Luo, S., Xia, X., Xi, Q., Wan, Y., Chen, L., Zeng, G., Liu, C., Guo, H., \& Chen, J. (2011). Enhancement of cadmium bioremediation by endophytic bacterium Bacillus sp L14 using industrially used metabolic inhibitors (DCC or DNP). Journal of Hazardous Materials, 190, 1079-1082.

[14] Tang, J., Ebner, A., Kraxberger, B., Leitner, M., Hykollari, A., Kepplinger, C., Grunwald, C., Gruber, H. J., Tampe, R., Sleytr, U. B., IIK, N., \& Hinterdorfer, P. (2009). Detection of metal binding sites on functional S-layer nanoarrays using single molecule force spectroscopy. Journal of Structural Biology, 168, 217-222.

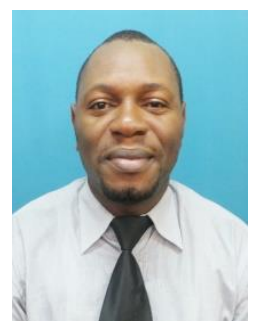

Emenike C. U. is a post-doctoral research fellow at the Centre for Research in Waste Management, University of Malaya (UM). Dr Emenike obtained his B.Sc degree (microbiology/biochemistry) from University of Nigeria, the M.Tech (environmental management) and the PhD (environmental toxicology \& bioremediation) degrees from UM. He has served UM in various research projects for a period of six years. He has experience in environmental toxicology, remediation technologies, waste management and risk assessment. $\mathrm{He}$ is versatile with systems that are pivotal to biostimulation, bioaugmentation and bioconversions as required in remedying polluted sites and waste generation systems. His roles in teaching, 
course development and mentoring have been overwhelmingly positive. Dr Emenike has written and published a number of scientific articles in international journals and papers in proceedings, and contributed chapters to books edited by others. 